\title{
Orocutaneous Fistula
}

National Cancer Institute

\section{Source}

National Cancer Institute. Orocutaneous Fistula. NCI Thesaurus. Code C127824.

An abnormal communication between the skin and the oral cavity. 